\title{
An Examination of Somali Parents' Interaction with Public Schools: Complicating Family Diversity in Educational Contexts
}

\author{
Wangari Gichiru \\ Central Connecticut State University \\ Connecticut, USA
}

\begin{abstract}
In this article I examine the experiences of recently immigrated Somali refugee families in their interaction with U.S. urban public schools where their children attend school. The experience of Somali refugees in the U.S. complicates the notion of family diversity, which goes beyond race, ethnicity, class, and gender to include differences in family structures and processes as well. With increasing diversity in public schools, there is a need for the teaching community to develop dispositions and understandings that are inclusive of various dimensions of family diversity. Immigrant experiences in the U.S. combined with the specific context of Somali refugee immigrants adds a nuanced dimension of diversity, especially in educational contexts where families must interact with schools on a regular basis. This study suggests that teachers must acquire knowledge of diversity among families and their complex, often changing structures and processes so that they can better understand and attend to the needs of Somali students.
\end{abstract}

\section{Introduction to Somalian Immigrant Families}

In this article, I examine the experiences of recently immigrated Somali refugee families in their interaction with urban public schools in the United States where their children attend school. Children from diverse immigrant families continue to be one of the largest growing populations of students attending U.S. public schools. Of these families, an increasing number constitute sub-Saharan refugees from Somalia, owing to civil unrest that has continued for more than two decades (Adams \& Kirova, 2007a). This increase in immigrant children in schools presents a challenge for teachers and parents for several reasons. One the one hand, recently emigrated families, especially those who are involuntary migrants forced to flee their country, face the challenge of divided families, economic hardship, and socio-cultural-linguistic alienation. 
In the context of Somali refugees, two aspects of life that have been severely affected by the politics in Somalia are family structure and education. Political unrest and involuntary migrations have disrupted traditional family structures and separated families as they flee their home country. The unrest has also left Somalia without any formal programs of education and systems of learning (Shome, 2011). Added to these circumstances, most Somali families and their children have little knowledge of the culture or the educational processes in U.S. public schools. On the other hand, schools are unprepared for working with diverse immigrant families and often lack programs, policies, or successful models that can facilitate interaction between Somalian parents and teachers. In addition, most teachers and administrators in public schools are White, middle class, and monolingual with little exposure to diversity among immigrant families and often lack multicultural competencies to address the academic needs of culturally diverse students (Sleeter, 2008).

The challenges of immigrant parents, children, and their teachers call for programs and strategies to facilitate communication between diverse parents and the schools their children attend (Roy \& Roxas, 2012). Immigration of Somali refugee families adds another dimension to the complexity of family diversity and how schools understand and work through these complexities has implications for the academic success of immigrant children in U.S. classrooms. In traditional classrooms, diversity is understood as difference in race, ethnicity, class, and gender at the cost of variations and intersections that go beyond these four categories (Turner-Vorbeck, 2005). Turner-Vorbeck notes that equity in education aimed at addressing the needs of all students, including those from diverse families, begins with teacher education programs and educators developing a more nuanced conceptualization of family diversity that takes into account the complex, often changing diversity of structures and processes within and among recent immigrant families.

With this in mind, this qualitative study examines how recently arrived Somali families experience, understand, and engage with U.S. public schools. As an immigrant from East Africa and now a scholar in the U.S., I empathize with Somali families and their experiences with U.S. schools. At the same time, as a teacher in the U.S. public education system, I am acutely aware of the struggles of fellow teachers as they grapple to serve students from diverse family backgrounds different from their own. Straddling both worlds, that of being an African immigrant in the U.S. and a K-12 teacher and teacher educator, has given me a unique opportunity for bridging the gap between immigrant families and the schools their children attend. I am aware of both worlds - the world of an immigrant from Africa and the professional world of a teacher in the U.S. I see myself as a bridge between the two by way of engaging in multicultural research aimed at developing teachers' understanding of diversity among families so that all students, including recently arrived Somali children, experience academic success.

\section{Review of Research}

Immigrant families must negotiate the culture of formal education, including the norms of family and diversity in U.S. schools. For Somali families, the negotiation is complicated by the status of being a refugee, implying involuntary immigration, and a long history of trauma that results in reducing parents' capacity to be stable supporters for their children (Gichiru, 2012a). Fleck and Fleck (2013) posit that the struggles of involuntary immigrants, such as Somali refugees, stems from the discrepancies in their parenting practices and cultural values of their home country on one hand, and the sense of loss they feel because of the differing values and 
expectations in their adopted country, on the other. In addition, immigrant parents experience numerous economic and social stress factors as they attempt to cope with daily life without the familiar support system of family and friends and the comfort of their culture of origin. Stress factors such as unemployment, underemployment, multiple jobs, shifts in traditional genderbased economic roles, language acquisition, realignment of parental authority, separation of family members, peer pressure, intergenerational values, and differing cultural beliefs impede immigrant children's academic success and threaten parents' positive interaction with social institutions (Fleck \& Fleck, 2013, McBrien, 2005).

Immigrant parents feel alienated from school activities, are unsure of expectations of their roles within education, often move in search of work or to reconnect with displaced relatives; therefore, they may appear less engaged in their children's schools (Hoover-Dempsey, Walker, \& Sandler, 2005). When families settle in one place, many parents are not able to help their children with homework even though they are supportive of and value their children's education (Nderu, 2005). Thus, displaced refugee families face significant challenges that diminish their capacity to build strong communication and problem solving skills when faced with a different cultural environment (USCRI, 2015).

Studies directed at understanding parental involvement of specific groups of refugees from around the world in their children's education have found that refugee children's poor school performance is partly attributed to dysfunctional home school relationships such as misunderstandings, mistrust, and general breakdown of communication (BRYCS, 2015; Roxas, 2008). Ghaffar-Kucher (2006) notes that approaches to addressing the challenges faced by immigrant students and their parents in schools continues to be entrenched in the classic assimilationist model. She writes, "Rather than constructing new ways to accommodate and embrace the added diversity that immigrants bring to educational settings, schools have been viewed as the primary vehicle for 'assisting' immigrant students to assimilate" (p. 3).

Assimilation, a concept that has influenced U.S. education, is a process in which immigrants give up all traces of their old life in favor of the superior values of the place one immigrates to (Walker \& Serrano, 2006).

There is also a general failure of teachers to offer specific suggestions to parents on how they can help their children (Hoover-Dempsey, et al., 2005). Thus, given these complexities and the fact that education is at the center of the social and cultural process that enables a refugee coming to the U.S., American educators are forced to rethink their moral responsibilities in order to provide quality education for all children, including new arrivals (Ladson-Billings \& Tate, 2006). With increasing diversity among family structures, parenting processes, and communication patterns, there is a critical need for developing teachers' multicultural knowledge, skills, and dispositions to work with new forms of diversity within and among families present in schools and society.

Many schools respond to diversity by introducing multicultural educational reform for improving the educational experiences of students including Somali refugees (Oikonomidoy, 2015). To help teachers inculcate the capacity to conduct their work with more sensitivity towards multiculturalism, there is a need to further teachers' understanding of diversity beyond the categories of race, ethnicity, class, and gender. In today's educational contexts teachers would benefit from a more nuanced conceptualization of family diversity that takes into account the complex, often changing, diversity of structures and processes within and among specific immigrant families such as the Somalis and how such families understand their roles in the school system. Knowledge about how families perceive the educational experiences of their 
children viewed from the perspective of the family members must be represented in curricular decisions (Heitritter, 1999).

Therefore, in this study, I hope to expand teachers' knowledge of parental involvement related to a specific population-Somali refugee immigrants in an urban school district. I argue that there is need for U.S. teachers to rethink family diversity both in terms of its complex often changing physical structures and in terms of how such families conceptualize the education processes of their children and their current capacity to fully engage with schools. The two questions I researched are:

How do teachers perceive Somali parents' involvement in their children's education?

What are Somali parents' perceptions of their children's educational experiences?

In the next section of this article, I outline the theoretical framework and mode of inquiry that guided this study. I then lay out the methodology for the study followed by the findings and a brief discussion of the implications of this study.

\section{Theoretical Framework}

In order to examine parents and teachers' perceptions, I drew on the importance of cultural capital in family-school relationships and how cultural capital influences parental involvement in schools (Lareau, 1987). Lamont and Lareau (1988) define cultural capital as institutionalized high status cultural signals (e.g., attitudes, preferences, formal knowledge, behaviors, goods, and credentials) that one would need to succeed in society. In a study on the importance of cultural capital on family-school participation involving parents from workingand middle-class families, Lareau (1987) found that even though teachers made requests to all parents of both social classes to participate, the parents' social class provided them with unequal resources to comply with teachers' requests for participation. Lareau explained that the response to teachers' requests to participate was much higher for the middle-class school than the working-class school. As such, the amount of interaction or contact varied significantly between middle- and working-class parents with the schools that their children attended. The parents from the working class were reluctant to contact the school on academic matters and were uncomfortable with their interactions with the school. This was a result of their lower levels of academic attainment, relatively lower occupational prestige than the teacher, limited awareness of many aspects of their children's experience at school, limited communication skills, and limited time and disposable income to supplement and intervene with their children's schooling (Lareau, 1987). The opposite was true for the middle-class parents.

For Somali families who may not possess sufficient institutionalized high-status signals in the context of their new environment, e.g., lower levels of academic attainment in the U.S., lack of time due to hefty work schedules, Lareau's framework will be important to illuminate the Somali parents' interaction processes with the teachers in the schools that their children attend. In addition, given that many Somali families are now in a new context in the U.S., are ethnically different, and working hard to learn the English language, this theory offers an avenue to analyze their day-to-day processes and interactions in which they activate their accumulated "cultural capital to gain access to social settings [such as schools]" (Lareau \& Lamont, 1988, p. 163). 


\section{The Site}

\section{Modes of Inquiry}

The site for this study is an urban school district in the Midwest U.S. with a diverse population of almost two million people. According to census data (Census Viewer, 2010), the city is 39.97\% African American, 44.78\% Caucasian, 3.51\% Asian and other races, including African immigrants comprising $11.74 \%$. The city maintains the largest school district in the state and one of the largest in the nation. Among the African immigrants, the first wave of Somali refugees began arriving in 1995. Since then, the federal government has resettled more than 700 families in this area. This number is actually much higher owing to a large number of Somali secondary immigrants relocating from other states to work in the industrial sector. In this study, almost half the participants fell in this category of secondary migrants.

\section{Methodology}

This study used phenomenology as a qualitative methodology for exploring Somali refugee parents' interaction with teachers in U.S. public schools where their children attend school. Phenomenology as a method is useful in understanding meanings of events and interactions of ordinary people in particular situations (Smith, Flowers, \& Larkin, 2009). Phenomenologists do not assume they know what things mean to people they are studying; rather, they explore the subjective aspects of peoples' worlds and behaviors. Phenomenologists try to gain entry into the conceptual world of their subjects with the understanding that multiple ways of interpreting experiences are available to each participant through interaction. Individual reality, therefore, is socially constructed from experience and has a different meaning for each person based on his or her life context (Bogdan \& Biklen, 1998).

\section{Participants}

With the help of a local non-governmental organization working closely with the Somali refugee community in the area, I enlisted participants for the study. This was facilitated through a translator with English, Swahili, and Maay Maay language skills to help me communicate with the parents as well as serve as an interpreter. Sixteen parents participated in the study. All participants had a maximum of seven years in the U.S.. had children in school, had previously resided in the Dadaab or Kakuma refugee camps in Kenya prior to being resettled in the U.S., and had used the services of sponsors who acted as their school liaisons. Ten parents had relocated from other states. All parents were on welfare and had little or no formal education; 14 spoke the Maay Maay language, two of them partially understood English, and two spoke Swahili. While 10 parents had elementary school-age children, the other six had children in middle and high school. Nine parents were taking care of children who were not their biological children and eight families were headed by single women. The two males in the study had fulltime labor jobs in factories, a woman-parent worked as a cook in a charter school, and the rest of the women stayed at home or could not find work, therefore, were forced to stay home. 
Wangari Gichiru

\section{Data Collection}

In keeping with phenomenology, several forms of data were collected to get a rich understanding of the phenomenon under study. Data were collected through questionnaires, focus groups, and follow-up individual face-to-face interviews. Both the focus groups and follow-up interviews were semi-structured and participants were prompted to identify and talk about issues that were important to them. Each focus group session lasted two hours.

Data collection consisted of several steps. First, to gather background information, the translator orally administered a short questionnaire to each parent over a period of three days. I then split the 16 parents into two focus groups of eight each, depending on the proximity of where they lived. Two parents, one from each group, agreed to host each focus group session in their homes. Focus group A comprised of women, while focus group B had two men and six women, which included two married couples. Both focus interviews were held within the same week. After conducting the two focus group interviews, the translator and I debriefed about the interview process and worked together to translate and transcribe the interviews.

\section{Data Analysis}

In order to examine how Somali families make sense of their relationship with schools, I used interpretative phenomenological analysis to analyze the data (Smith, et al., 2009). To do this, I followed several steps as highlighted by Smith and his colleagues. First, I read and re-read the transcripts to immerse myself in the data. Second, I followed this with descriptive coding, searching for emergent themes and looking for connections among emergent themes. I repeated the same process for each focus group. Finally, I looked for patterns and emerging themes across the two focus groups. After an initial analysis of the focus group transcripts, I conducted several individual follow-up interviews with three parents from each focus group in the following months to clarify concepts or to seek further information. I analyzed and coded these interviews using the same steps. In the emerging themes, I paid attention to what the parents' awareness of school processes are, their interactions with each other in regards to their efforts to understand school processes, parent-teacher contact, their general perceptions of their children's experiences at school, and challenges the parents encountered.

\section{Teacher Perspective}

\section{Findings}

The quote below from a third grade teacher in this school district exemplifies a common theme running across teacher interviews. Teachers expressed difficulties working with Somali students and wished they could further understand the Somali family unitary composition, its structures, and processes within and among families in order to help them understand where Somali families are coming from in terms of their participation in their children's education. I wish I knew more about where these children were coming from, what their home is like, what their culture is like and what their parents are thinking. I looked a little bit on the internet and I don't think that's the place to get the information of what's really happening.

Even though many of the teachers said that they knew some of the Somali parents were "very determined and put a lot of effort to get their children to school," they nevertheless expressed frustration in promoting and maintaining ties with many recently arrived Somali immigrant parents in their classrooms. Some teachers conveyed that the parents "are just quiet on the times they come to school" and that the teachers had "no clue of what the children or their parents 
Somali Parents' Interaction with Public Schools

(Somali) are thinking." Some teachers agreed that communication with the Somali families was very difficult because "homework and other school instructions are sometimes not followed."

Teachers further talked of their frustrations with the general communication process because, in addition to the social and language barriers, communication was complex because the channels of communication included other players such as translators who included siblings or other students or professionals, sponsors, other parents or other relatives, and their children. As a fifth grade teacher put it:

The frustration part is that we cannot communicate with anybody, not with the students not with their parents, and we always have to require some translation and that is hard because sometimes the parents have the time to speak with us but there is no translator and that is very different than with any other group.

Sometimes you are dealing someone who says they are the 'uncle' or 'aunt' of the child and sometimes it is a sponsor.

This complexity in communication resulted in many teachers experiencing difficulty seeking timely solutions to issues involving their Somali students. This is because teachers felt that the communication process with many Somali families was complex, lengthy, and slow, because of the number of people involved and thus they shied away from it altogether. Many teachers expressed frustration because the lines of communication broke down repeatedly. This resulted in significant time delays between issue identification and solution. Teachers expressed that this turned communication with Somali families into a frustrating, expensive, and timeconsuming experience for them to undertake. It was expensive because on many occasions where translators were not provided by the school district, some teachers took it upon themselves to look for their own translators, who did the translation services for a fee (Gichiru, 2012b). The example below demonstrates another fifth grade teacher's frustration while seeking parental involvement to resolve behavior issues concerning one of her Somali students:

Who do I need to talk with? I need to talk with this child's mother. Maybe there is a cousin that I can talk to. I want to talk to your cousin's mother. Can you help me make that happen? I need a translator as well. Because the student that I am having trouble with will definitely not talk to their parents and there is no direct phone number.

A third grade teacher said he desired to talk to Somali parents about the behavior of two of his Somali students, but shied away because he did not know how to go about it:

One of the problems with the Somali kids is that I cannot communicate with their home. For example, if I want to communicate with Hamida's family, I know there are four or five there, Musa is one of them, I think there is an uncle who lives with them ... so we do not who is the head of the family.

One of the teachers explained some major effects of this time delay between issue identification and solution. She said that the child who understood teachers' difficulties in communication sometimes "got away" without the issue being resolved. This is because the child watched as the story occasionally became distorted because of the number of people involved or the child sometimes genuinely forgot some details of the issue altogether. This situation was expressed by a third grade teacher who said:

As a counselor, the sponsor felt one thing and advocated for the parent in his way but I thought the parent had another perspective but was not able to speak it. So there was a conflict. And the school had a different perspective. Of course the child said nothing. 
The teachers also found it difficult to get answers to questions that aroused their curiosity about Somali families home life and family structure. The following excerpt by a male second grade elementary teacher was representative of many teachers:

I would like to know how many people live in a house, how are girls treated, how are boys treated? In other words, what is the state of affairs in the Somali house? How do they live? And not just that, but [what] cultural things are expected of boys versus girls? Are boys expected to stay in the home? What is discipline like? What is the parent child connection? Are they nurtured, or are they expected to grow up quickly and take on adult responsibilities?

The above discussions with teachers shed light on several factors that affect the educational interactions between teachers and Somali parents. First, communicating was complex because of language barriers, translators and interpreters, children being used as interpreters, and teachers' frustration with the process. Second, teachers did not have knowledge of family structures and processes and who was the actual guardian. As the literature documents, unlike a traditional nuclear family, in Somalian culture, extended family and friends take on responsibilities for children when parents struggle. Third, parent-school personnel contact was strained and parents' ability to communicate with teachers was minimal in spite of teachers wanting to understand and navigate through Somali family structure and processes.

As Lareau's notion of cultural capital notes, cultural capital plays a major role in widening the gap between teachers and Somali refugee parents. Teachers' cultural capital creates barriers in terms of the degree of willingness to make an extra effort to overcome the challenges they face when communicating with parents. Teachers assume their time is more valuable and expect parents to assume all responsibility of their children. At the same time, findings indicate that teachers need professional development in specialized training to be able to work with Somali parents in terms of understanding cultural norms, family patterns and responsibilities, and family processes including educational expectations.

\section{Parent Perspective}

The excerpts below demonstrate that many parents were aware of school processes and were appreciative of the good work that teachers did for their children. At the same time, the excerpt that follows shows parents struggle to communicate with their children's teachers because of language barriers coupled with difficulties securing the services of translators. A mother from focus group A demonstrated the effort most parents put in their sometimes unsuccessful effort to help their children with their homework:

My children many times do it [homework] at home on their own. Other times I take them to another organization downtown when I am able to. Nobody helps my children at home to do homework because their father and I cannot read so I would like if only I would find someone to help my children at home with their homework so that I can see for myself how the children are progressing and how they are studying. This is what my heart wants. (Mother, focus group A) Most parents felt that teachers needed to understand and demonstrate more patience with their current predicament. Take for example this representative excerpt from a father from focus group $\mathrm{B}$ :

We do not know how we will speak to the teachers; we do not know where we will start or where to stop. We do not know the rules of the office at school. What makes us fear and especially the women is because we don't know the language. I 
Somali Parents' Interaction with Public Schools

do not know how to ask my teacher how my child is doing at school. We want someone who can translate for us at school. When we try to ask friends and neighbors, they have their own work and they have no time to take us there. That's what makes women not be able to communicate with the teachers. This is the major problem here because each one of us really wants to ask how our child is doing, but we can't even say "how much" in English.

The second father in focus group B said:

The problem we have is that when we go to work we come back late. Again, I myself have not gone to school. The English that I speak, I have learned in the street. I would like for my self to know how to read and write in English. That's my biggest problem. There are times when I get letters in the mail. Many times, the stay in my house for days before I know what is in them, sometimes they are doctors' appointment letters or they are from the school. They have to wait until I find someone to come and read them for me. The person who can read this letter has gone to work. When they get back, they are very tired at night and the last thing they want to do is to read a letter so I try to look for a different person.

The above excerpts indicate several challenges faced by parents. While the challenges are similar to those faced by teachers, teachers and parents have differing perspectives on the cause and solution to these challenges. Parents encountered structural challenges such as long work hours, struggles with financial stability, cultural misunderstandings, and stated that teachers did not fully understand the reasons that kept them from participating in school events. Structural and cultural challenges were compounded by their English language skills on the one hand and teachers' lack of resources in getting mediators who spoke the languages of Somali parents, on the other.

\section{Trust Issues between Parents and Teachers}

In terms of parental communication skills as cultural capital, even though the parents put in a lot of effort to have teachers' letters translated so that they could sign them, they were also wary of the sincerity of the same translators when they were available. Take for example this parent from focus group A:

Initially when I was in the other state, I had a translator who was Somali who when I gave him a letter to read for me, many times she used to say, "this letter doesn't say anything" let's throw it in the garbage. But later I came to realize that that letter is for appointment for public aid food share renewal. By the time I knew, my food had been discontinued. So am not sure that the translator I find will tell me really what is written in these school documents.

Two women in the same focus group on hearing this chimed in and addressed the translator who was helping with the focus groups to which other parents jumped in, in the excerpts that follow:

Juma [research translator], please do not cheat us or trick us. Please mama Asafi, may be Juma will not translate the things the way they are and will trick us? If he does not do the correct translation, we will sue him. But how, do we sue him and he is a senior. How do I tell the teacher I do not trust the translator? (Mother, focus group A) 
If what we are saying does not go through, we shall look for another translator to do this job for us. Do you realize the trouble Somali translators have caused us?

Why would we desire another Somali translator? We want someone who speaks Maay Maay, so that they can translate it well! (Mother, focus group A)

Parents also revealed they were distrustful of signing any documents they did not understand because they had prior knowledge from the resettlement agencies about how they were to handle different issues. Some of the resettlement training information offered by the United Nations High Commissioner for Refugees were misunderstood by parents and conflicted with information given by schools. This misunderstanding prevented parents from accomplishing school tasks such as signing documents, which the teacher viewed as disinterest or being lax in participating in school activities. For example, a father in focus group B explained that an orientation lesson cautioned parents from signing documents that they did not understand, which made them view any document requiring signatures with suspicion:

Now when the children bring the letters, they tell us "put a sign here" and we do not know what this letter is saying. So, take this message to the teachers saying that Somali Bantus have never been to school, and we do not know how to read or write. And these people (Resettlement agencies) told us not to put signatures on documents we do not understand.... When they bring these letters and they just tell us to sign here, we don't know whether the letter contents are risky or not. They should not send us something that will later land us in trouble with our children and relatives.

The above excerpts illustrate that parents were grappling with major trust issues as far as communicating with schools was concerned. First, level of trust with translators; second, confusion between what they were told during their orientation into a new culture and what schools expected of them; and third, lack of English language communication skills made them suspicious of what they were told. The mistrust of translators, lack of school resources, and lack of cultural capital reveal the complexity of how Somali families grapple to adjust to their new home country and school expectations. It also demonstrates that many families still depended on the knowledge gained from orientations by resettlement agencies in an effort to keep their families intact.

\section{Cross Cultural Knowledge}

Parents unanimously appreciated the role teachers played in their children's life. In addition, they recognized their dependence on the teacher, whom they viewed as part of their family structure. Parents expected teachers to join the efforts to raise the child by taking over some tasks that families were not able to do because they viewed teachers as a part of their family. This demonstrates a disconnect between parents' view of teachers as part of the family structure and the norms of U.S. education and parenting. A parent from focus group A shared:

There are two parents, one is the one who is teaching you at school, and the other is the one who has given birth to you. Even if the teacher has not given birth to this child, their approach to the child is even better than the way we treat them. So they are the second parents.

A parent from focus group B said:

For example, my child Habiba, sometimes, they give her clothes to change, and especially the blouse. Sometimes skirt and blouse. Because they know that I don't 
have a husband or anyone to help me so am very grateful. They are also a parent to this child. So they understand my condition.

In the same light, parents concurred that it should be common sense for teachers to know what aspects are important to Islamic culture, such as Ramadan and religious dietary norms. A woman from focus group A said during the follow-up individual interviews:

Our children are young and they do not know what food is "halal" or "haram" purified or not purified. You know everything they see they eat, including pork; they just eat everything in school. And we know that the teachers know what Muslims eat and do not eat. It's not a must for them to be told, do not give him or her or that, it is not a must that the teachers should wait for a parent to come and say do not give this or that to my kid. Because all children are in class learning and they are hungry, whatever you give them, they can eat.

A parent from focus group B realized it was their duty to do "what the teacher cannot do," for example making sure that the child has enough to eat or enough rest so that he or she is ready:

The good things that these teachers are doing for the kids, we cannot do. The child has 5 days with the teacher, so we only have this child on Saturday and Sunday. Or when schools are off session. The way the teachers control the children, we can't control them like that. This is because when the child sits down, the teacher sits down. When the student stands up, the teacher stands up too.

It was apparent that parents held the teachers in very high esteem, to the point that they viewed the teachers as co-parents in the effort to raise their children. In contrast, this is a role that the teachers did not see themselves in, as demonstrated by this quote below from a middle school science teacher:

Why on earth would you send your children to school with dirty socks and clothes? You know, you can see the skin, the body has not been maintained. They look like they almost rolled out of bed, put the clothes they had on yesterday and then sent them out the door. That I think needs to be addressed.

The above three excerpts show the cultural gap between parents and teachers. The first excerpt shows that Somali parents assumed the parent understood what the Somali family's cultural norms and expectations are. Teachers, on the other hand, did not understand those cultural expectations. The second excerpt shows that, on one hand, many parents saw their children's teachers as second parents within their family structure; on the other, teachers did not see themselves fulfilling the role of parents.

\section{Discussion and Implications}

In this article, I examined the experiences of recently immigrated Somali refugee families in their interaction with U.S. urban public schools where their children are enrolled. Somali refugee families add another dimension to the complexity of family diversity, and how teachers understand and work through these complexities has implications for the academic success of immigrant children in U.S. classrooms. Overall, the study showed that there is a disconnect between views of parental involvement by teachers on one hand and those of Somali families on the other. As findings indicate, and supported by the reviewed literature and theoretical framework, this disconnect is rooted in, among other things, a general misunderstanding of who 
is included in the Somali family structure from the parents' perspectives and who is included from the teachers' perspectives.

The ways in which Somali families and teachers made sense of the difficulties each experienced was partly a result of the differing understanding of Somali family unitary composition, social structures, and family responsibilities. The real concern was not disinterest as the teachers might have concluded, but that there is an inconsistent understanding between what the parents think the family support structure is and teachers' understanding of the same. Parents saw teachers as cultural allies and family members in the form of second parents who knew "various aspects of their culture and expected them to execute those norms on the Somali parents' behalf." This is a view that the teachers did not share. This explains why some parents misunderstood teachers' kind gestures as playing the role of second parents. On the other hand, this perception resulted in teachers viewing parents as falling short in their parental duties. Informed understanding of this gap expands teachers' understanding of family diversity in that teachers might begin to see the perspectives of parents.

Teachers also grappled with what they considered to be complex communication processes because of the number of people involved in a Somali family. Knowledge of the nuances of Somali family's internal composition and social structure would be beneficial to teachers. This very notion of understanding extended family as constituting a Somali family and how the internal structure of the family is socially structured helps teachers' understandings in two ways. First, many families are headed by one parent, but when resettled, an uncle, aunt or grandparent shares guardianship of children as part of the immediate family. This means that the internal composition of the Somali family sometimes becomes an elusive, amorphous structure that the teacher finds complex. Second, the social structure is also different in that parents lack cultural capital [e.g., literacy skills, community connections, and driving skills (Lareau, 1987)] and find themselves dependent on their children, translators, and even teachers.

This study also makes recommendations for teachers, teacher education programs, and further research. There is a need for schools and teachers to develop teacher dispositions and understandings that are more inclusive of family diversity in order to fully engage immigrant parents in their children's education. This study suggests that teachers must seek ways to not only further understand the home culture of children they teach, but also view themselves in the narratives of their students' families. For example, teachers might try to empathize with parents engaged in tracking lost relatives; living with reunited relatives; engaging with sponsors, translators, and social workers; or to learn about children living in single-parent homes. It is important for in-service teachers to pay close attention to the complexity of the family and culture as an integrated concept that influences behaviors and identities. What is suggested is a systematic, intentional process of reflecting on one's beliefs, unlearning some of those beliefs, and being open to new forms of cultural knowledge. Teacher preparation programs could focus on community partnerships to prepare teachers who have the capacity to teach diverse students, including those from recently emigrated communities. Teacher candidates might be sensitized to the ever-changing family diversity of different groups of people who will make up families represented in their classrooms. 


\section{References}

Adams, L. D., \& Kirova, A. (Eds.). (2007a). Introduction to part 1: Multiple global issues for immigrant children and the schools they attend. In L. D. Adams \& A. Kirova (Eds.) Global migration and education: Schools, children and families. Mahwah, NJ: Lawrence Erlbaum Associates, Publishers.

Adams, L. D., \& Kirova, A. (Eds.). (2007b). Introduction: Global migration and the education of children. In L. D. Adams \& A. Kirova (Eds.). Global migration and education: Schools, children and families. Mahwah, NJ: Lawrence Erlbaum Associates, Publishers.

Adams, L. D., \& Shambleau, K. M. (2007). Teachers, childrens and parents perspectives on newly arrived children's adjustment to elementary schools. In L. D. Adams \& A. Kirova (Eds.), Global migration and education: Schools, children and families (pp. 87-102). Mahwah, NJ: Lawrence Erlbaum Associates, Publishers.

Bogdan, R. C., \& Biklen, S. R. (1998). Qualitative research for Education: An Introduction to theroy and methods ( $3^{\text {rd }}$ ed.). Boston: Allyn and Bacon

BRYCS. (2015). Bridging refugee youth and children's servies: Targeted resources for professionals. Retrieved November $2^{\text {nd }} 2015$ from http:/www.brycs.org/

Census Viewer. (n.d.). Milwaukee, Wisconsin population: Census 2010 and 2000 interactive map, demographics, statistics, quick facts. Retrieved from http://censusviewer.com/city/WI/Milwaukee

Creswell, J. W. (2003). Research design: Qualitative, quantitative and mixed methods approaches to research (2nd ed.). Thousand Oaks CA: SAGE.

Fleck, J. R., \& Fleck, D. T. (2013). The immigrant family: Parent-child dilemmas and therapy considerations. American International Journal of Contemporary Research, 3(8), 13-17.

Ghaffar-Kucher, A. (2006). Assimilation, integration, or isolation? (Re)Framing the education of immigrants. Current Issues in Comparative Education, 9(1), 3-7.

Gichiru, W. (2012a). Challenges and prospects of providing critical educational opportunities for Somali refugees in the United States. In M. Knoester (Ed.), International struggles in critical democratic education (pp. 49-68). New York: Peter Lang.

Gichiru, W. (2012b). Refugee education in resettlement: Teachers experiences in meeting the educational needs of Somali refugees in the U.S. Unpublished Dissertation. Curriculum and Instruction. The University of Wisconsin-Madison, Madison, WI.

Heitritter, D. L. (1999). Somali family strength: Working in the communities. Retrieved from family and childrens service: http://www.brycs.org/documents/upload/SomaliFamilyStrengthReport.pdf 
Hoover-Dempsey, K. V., Walker, J. M. T., \& Sandler, H. M. (2005). Parents' motivations for involvement in their children's education. In E. N. Patrikakou, R. P. Weissberg, S. Redding \& H. J. Walberg (Eds.), School-family partnerships for children's success (pp. 40-56). New York: Teachers College Columbia University.

Ladson-Billings, G., \& Tate, W. F. (Eds.). (2006). Education research in the public interest:social justice, action, and policy. New York: Teachers college press

Lareau, A. (1987). Social class differences in family school relationships: The importance of cultural capital. Sociology of Education, 60(2), 73-85.

Lamont, M., \& Lareau, A. (1988). Cultural capital: Allusions, gaps and glissandos in recent theoretical developments. Sociological Theory, 6(2), 153-168.

McBrien, L. J. (2005). Educational needs and barriers for refugee students in the United States: A review of the literature. Review of Educational Research, 75(3), 329-364.

Nderu, E. N. (2005). Parental involvement in education: A qualitative study of Somali immigrants in the twin cities area. Unpublished Doctoral Dissertation, University of Minnesota, Minnesota.

Oikonomidoy, E. (2015). Positioning multicultural education across the mirror of globalization. Multicultural Education, 22(3/4), 39.

Roxas, K. (2008). Who Dares to Dream the American Dream? The success of Somali Bantu male students at an American high school. Multicultural Education, 16(2), 2-9.

Roy, L. A., \& Roxas, K. C. (2012). Whose deficit is this anyhow? Exploring counterstories of Somali Bantu refugees' experiences in "doing school". Harvard Educational Review, 81(3), 521-541.

Shome, S. (2011). Assimilation of Somali refugees and immigrants in the kansas city area (Order No. 3468858). Available from ProQuest Dissertations \& Theses Global. (889104300). Retrieved from http//0-search.proquest.com.www.consuls.org/docview/889104300?acco untid $=9970$

Sleeter, C. E. (2008). Preparing White teachers for diverse students. In M. Cochran-Smith, S. Feiman-Nemser, J. D. McIntyre, \& A. O. T. Educators (Eds.), Handbook of research on teacher education: enduring questions in changing contexts (pp. 559-582): Routledge.

Smith, J. A., Flowers, P., \& Larkin, M. (2009). Interpretative phenomenological analysis: Theory, method and research. Thousand Oaks, CA: Sage Publications Ltd.

Turner-Vorbeck, T. A. (2005). Expanding multicultural education to include family diversity. Multicultural Education, 13(2), 6-10. 
Somali Parents' Interaction with Public Schools

UNHCR. (2015). Refugees in the horn of Africa: Somali displacement crisis.

Retrieved from http//data.unhcr.org/horn-of-africa/regional.php

U. S. Commitee for Refugees and Immigrants. (2015). Refugee family strengthening programs. Retrieved from http $/ /$ www.refugees.org/about-us/contact.html

Walker, J. P., \& Serrano, A. M. (2006). Formulating a cosmopolitan approach to immigration and social policy: Lessons from American (north and south) indigenous and immigrant groups. Current Issues in Comparative Education, 9(1), 60-68. 